\section{Stimulation seeking behavior}

Helga Peter

Marburg, Deutschland
Bezeichnung für Verhaltensweisen von schläfrigen Personen, die versuchen, sich durch Stimulation wach zu halten. Beispiele sind rasende Geschwindigkeit beim Autofahren, Hören sehr lauter Musik oder unterschiedlichste körperliche Betätigung wie beispielsweise trommelnde Bewegungen mit den Extremitäten, Sich-Kratzen, Umherlaufen, Rauchen, Fensteröffnen. 